\title{
Enhanced Electrical Insulation and Heat Transfer Performance of Vegetable Oil Based Nanofluids
}

\author{
Wei Yao $\left(\mathbb{D}\right.$, Zhengyong Huang $\left(\mathbb{D}\right.$, Jian Li $\mathbb{D}^{\mathbb{D}}$, Liya Wu $\mathbb{D}$, and Chenmeng Xiang \\ The State Key Laboratory of Power Transmission Equipment and System Security and New Technology, College of Electrical Engineering, \\ Chongqing University, Chongqing 400044, China
}

Correspondence should be addressed to Zhengyong Huang; huangzhengyong@cqu.edu.cn and Jian Li; lijian@cqu.edu.cn

Received 22 November 2017; Revised 4 March 2018; Accepted 11 March 2018; Published 15 April 2018

Academic Editor: Stefano Bellucci

Copyright (C) 2018 Wei Yao et al. This is an open access article distributed under the Creative Commons Attribution License, which permits unrestricted use, distribution, and reproduction in any medium, provided the original work is properly cited.

\begin{abstract}
Nanoparticles enhance the electrical insulation and thermal properties of vegetable oil, and such improvements are desirable for its application as an alternative to traditional insulating oil for power transformers. However, the traditional method of insulating nanofluids typically achieves high electrical insulation but low thermal conductivity. This work reports an environmentally friendly vegetable oil using exfoliated hexagonal boron nitride (h-BN) showing high thermal conductivity and high electrical insulation. Stable nanofluids were prepared by liquid exfoliation of h-BN in isopropyl alcohol. With 0.1 vol.\% of the nano-oil, the AC breakdown voltage increased by $18 \%$ at $25^{\circ} \mathrm{C}$ and $15 \%$ at $90^{\circ} \mathrm{C}$. Both the positive and negative lightning impulse breakdown voltages of the nanooil were also enhanced compared with those of the pure oil. Moreover, the thermal conductivity of the nano-oil increased by $11.9 \%$ at $25^{\circ} \mathrm{C}$ and $14 \%$ at $90^{\circ} \mathrm{C}$. Given its high thermal conductivity, the nano-oil exhibited faster heating and cooling effects than the pure oil. Nano-oils with an electric field (either DC or AC) displayed a faster thermal response than that without an electric field. The reason is that h-BN is oriented under the electric field and formed a thermal network to increase the heat transfer.
\end{abstract}

\section{Introduction}

Nanofluids, formed by adding nanoscale particles to the base fluid, are stable and homogenous suspensions that present advanced performance of electrical insulation and thermal conductivity [1-6]. In recent years, nanofluids with various kinds of nanoparticles have promising potential applications in fields including electric engineering, microelectronics, biomedicine, and energy storage [7-10]. Vegetable oil, which is a new kind of environmentally liquid dielectric, has drawn attention as a potential alternative to traditional mineral oil for power transformers in electric engineering [11]. Improving insulation and thermal conductivity of vegetable oil is a benefit to reduce the size of power transformer and improve long-term stable operation.

Nanofluids with long-term stability are the basis for ensuring improved physical and electrical properties as well as heat transfer performance. Preparation of nanofluids also has two methods: one-step method and two-step method. Most literature reported that the nanofluids prepared by two-step method have a good stability $[12,13]$.
The nanoparticles in nanofluids have three main surface forces between each other, such as van der Waals force, electrostatic force, and steric hindrance forces. The classical Derjaguin-Landau-Verwey-Overbeek (DLVO) theory indicated that stability of fluids is mainly determined by electrostatic and van der Waals interaction forces. DLVO theory is valid at macro and macron scale but no longer applicable to nanoscale size [14]. Although the extended DLVO (xDLVO) approach and other theories were proposed, nanofluids with nanolevel systems show complex behavior due to multiscale collective effects [15]. The main factors affecting the dispersion stability of nanofluids include the size of the particles, the dielectric constant, and the Zeta potential of the nanofluids [16]. For unstable nanofluids, the surface of the nanoparticles adsorbs a layer of surfactant or dispersant to form the stable nanofluids [17].

In the field of liquid dielectric, existing studies have focused mainly on mineral oils with nanoparticles [18-21]. Compared with mineral oil, vegetable insulating oil has a higher AC and DC breakdown voltage [22]. The addition of a certain amount of magnetic conductive nanoparticles, 
such as $\mathrm{Fe}_{3} \mathrm{O}_{4}$, to either vegetable insulating oil, improves its positive $(\sim 37.4 \%)$ and negative $(\sim 11.8 \%)$ lighting impulse breakdown voltages [23]. In addition, nanoparticles can form negatively charged particles in a short time period and consequently affect the development of the streamer. However, the addition of $\mathrm{Fe}_{3} \mathrm{O}_{4}$ semiconductors above $0.014 \% \mathrm{w} / \mathrm{w}$ dramatically reduces the breakdown voltage of vegetable oil, which does not satisfy the requirement of insulating oil used in real transformers.

Moreover, nanofluids enhance the breakdown voltage of base fluids, one of the most challenging works is to improve the heat transfer. Compared with the conventional solid-liquid two-phase suspension with larger particles, the dispersion stability and the effective thermal conductivity of nanofluids are considerably improved because of the nanosized particles and the large contact area between the particles and the base fluid. Eastman et al. [24] used oleic acid as dispersant to disperse $\mathrm{Cu}$ particles of $3 \mathrm{~nm}$ radius into ethylene glycol (EG), and the effective thermal conductivity of the nanofluids was increased by approximately $40 \%$ when the volume fraction of $\mathrm{Cu}$ particles was $0.2 \%$. Zheng et al. [25] utilized graphite suspensions (graphene volume fraction: $1 \%)$ to examine the thermal conductivity of different base fluids; they found that the effective thermal conductivity of the EG and poly $\alpha$-olefin oil base solutions was increased by $150 \%$ and $200 \%$, respectively. Ettefaghi et al. [26] added carbon nanotubes to engine oil and observed an increase by $13.2 \%$ when the mass fraction was $0.1 \%$ and so on. Numerous experiments indicated that the effective thermal conductivity of the nanofluids was substantially greater than that of the traditional solid-liquid two-phase suspension.

However, these high-thermal-conductivity materials are either conductors or semiconductors. The mass fraction of nanoparticles in base fluids shows high thermal conductivity, but it is not beneficial to the insulation properties of liquid dielectrics. Thus, the insulating nanomaterials can ensure or even improve the insulation performance of liquid dielectric, and nanoparticles with high surface area, such as twodimensional materials, are good choices for thermal fluids. The h-BN nanoparticles called white graphene have a high thermal conductivity $(\sim 360 \mathrm{~W} / \mathrm{m} \cdot \mathrm{K})$ and insulation characteristic with band gap ( 4-6eV) [27]. Thus, the discovery of this nanomaterial can enhance both the electrical insulation and thermal properties of the vegetable oil.

This research aims to study the effect of insulating BN nanoparticles on the insulation and thermal conductivity of vegetable oil. The different electrical properties of nano-oil prepared by two-step method are presented and discussed. Next, we show the thermal conductivity varying with different concentration of nanoparticles and analyze the heating and cooling response of nano-oil under effect of electric field.

\section{Experimental}

2.1. Preparation of Nanofluids. Boron nitride was prepared by liquid exfoliation method. Micrometer-sized h-BN (Aladdin, $1-2 \mu \mathrm{m}, 98 \%)$ was sonicated for $24 \mathrm{~h}$ in isopropyl alcohol at room temperature and then centrifuged at $3000 \mathrm{rpm}$ for $10 \mathrm{~min}$ to collect the supernatant. The supernatant was
TABLE 1: Basic properties of the FR3 insulating oil.

\begin{tabular}{lc}
\hline Parameter & FR3 insulating oil \\
\hline Appearance & Bright and clear \\
Density $\left(\mathrm{kg} \cdot \mathrm{m}^{-3}, 20^{\circ} \mathrm{C}\right)$ & 0.92 \\
Acid number $\left(\mathrm{mgKOH} \cdot \mathrm{g}^{-1}\right)$ & 0.032 \\
viscosity $\left(\mathrm{mm}^{2} \cdot \mathrm{s}^{-1}, 40^{\circ} \mathrm{C}\right)$ & 24.1 \\
Pour point $\left({ }^{\circ} \mathrm{C}\right)$ & -21 \\
Flash point $\left({ }^{\circ} \mathrm{C}\right)$ & 316 \\
Interfacial tension $(\mathrm{mN} / \mathrm{m})$ & 24 \\
Breakdown voltage $(\mathrm{kV})$ & 56 \\
Dissipation factor $\left(\%, 90^{\circ} \mathrm{C}\right)$ & 1.55 \\
Relative dielectric constant $\left(90^{\circ} \mathrm{C}\right)$ & 2.86 \\
Volume resistivity $\left(\times 10^{10} \Omega \mathrm{m}, 90^{\circ} \mathrm{C}\right)$ & 1.1 \\
\hline
\end{tabular}

vacuum-dried in an oven for $48 \mathrm{~h}$. Then, the white powder was collected and grinded.

The collected powder was dispersed in vegetable insulting oil (FR3 mechanized form Cargill, Basic properties in Table 1) and sonicated at room temperature for $30 \mathrm{~min}$ for different volume fractions $(0.015,0.03,0.06$, and 0.1 vol.\%). Prior to electrical and thermal characterization, the nano-oil and the FR3 were dried at $85^{\circ} \mathrm{C}$ under $50 \mathrm{~Pa}$ for $48 \mathrm{~h}$. The volume fraction was calculated as follows:

$$
\varphi=\frac{m_{p} / \rho_{p}}{m_{p} / \rho_{p}+m_{\mathrm{oil}} / \rho_{\mathrm{oil}}} \times 100 \%,
$$

where $\varphi$ is volume concentration, $m_{p}, m_{\text {oil }}$ is the weight of nanoparticles and vegetable oil, and $\rho_{p}, \rho_{\text {oil }}$ is the respective density where $\rho_{\mathrm{BN}}=2200 \mathrm{~kg} / \mathrm{m}^{3}, \rho_{\text {oil }}=920 \mathrm{~kg} / \mathrm{m}^{3}$ at a temperature of $20^{\circ} \mathrm{C}$.

2.2. Electrical Properties of Nano-Oil. The measurement of dielectric constant, dielectric loss factor, and electrical resistivity were performed using BAUR DLT C dissipation factor measurement equipment, followed by the execution of IEC 60247. The test method of AC and DC breakdown voltage were in accordance with the IEC60156 (Insulating liquidsDetermination of the breakdown voltage at power frequencytest method). The adopted test electrode was copper electrode with a class spherical electrode radius of $13 \mathrm{~mm}$ and an electrode gap of $2.5 \mathrm{~mm}$. The test temperature was $25^{\circ} \mathrm{C}$ and $90^{\circ} \mathrm{C}$, and the frequency of AC breakdown voltage was $50 \mathrm{~Hz}$. The nano-oil was placed in a test oil cup to avoid the effects of microwater and pollutants and set aside for $5 \mathrm{~min}$ prior to testing to ensure the absence of bubbles in the nano-oil. During the test, the voltage was increased by $2 \mathrm{kV} / \mathrm{s}$, followed by breakdown. A 5 min test interval was set to avoid the effects of bubbles and product discharge. The test was repeated six times.

The lighting impulse breakdown, which is a key parameter in the insulation of dielectric liquids, was measured in accordance with the IEC 60897 standard. The nano-oil was subjected to lightning striking test by rising voltage method. The lightning impulse was provided by a six-stage impulse generator, of which the maximum voltage was $900 \mathrm{kV}$ for 


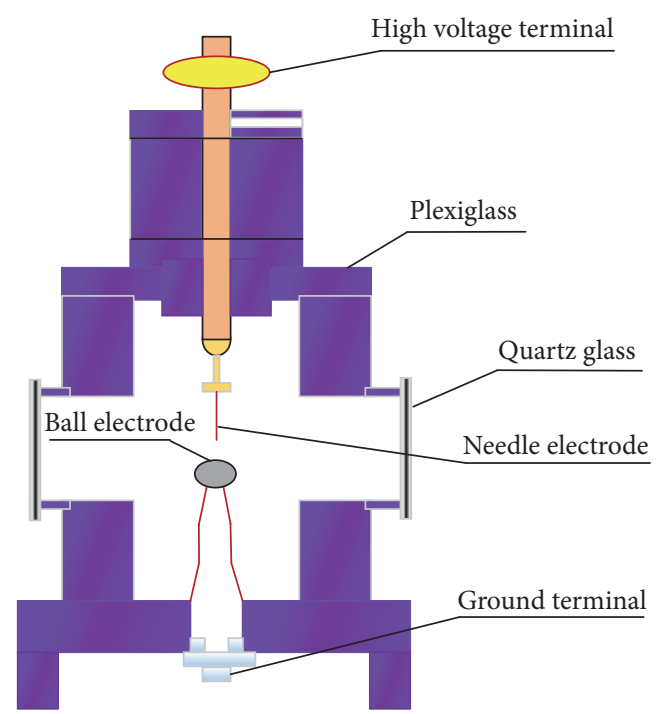

FIGURE 1: Sketch of electrode setup and oil vessel for lightning impulse breakdown experiments.

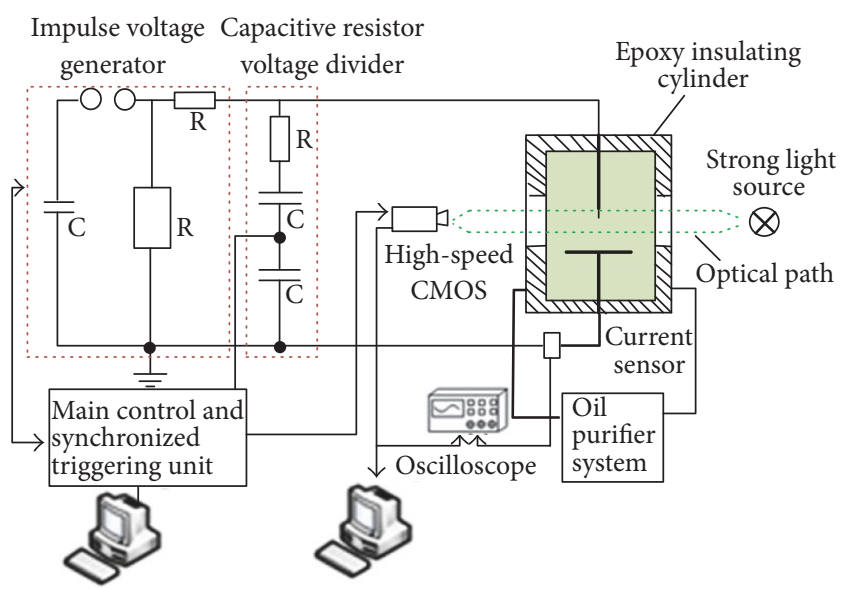

FIGURE 2: Diagram of the test system for discharge in oil.

an energy of $33.74 \mathrm{~kJ}$. This impulse generator was used to deliver a standard lightning impulse of $1.2( \pm 30 \%) / 50 \mu \mathrm{s}$ $( \pm 20 \%)$ and a switching impulse of $250( \pm 20 \%) / 2500 \mu \mathrm{s}$ $( \pm 60 \%)$. The voltage waveform was measured by a highvoltage capacitive resistor voltage divider and recorded by an oscilloscope (LeCroy WaveRunner 610zi). The sampling rate was $10 \mathrm{GS} / \mathrm{s}$, and the bandwidth was $1 \mathrm{GHz}$. The lightning impulse breakdown voltage test device is shown in Figure 1. The high-voltage electrode served as the needle electrode. The radius of the curvature of the cone top was $40 \mu \mathrm{m}$, and the low-voltage electrode was the ball electrode of $13 \mathrm{~mm}$ diameter. The gap distance of the electrodes was $15 \mathrm{~mm}$. The breakdown experiments in liquid is shown in Figure 2, which illustrates the development pattern of the nano-oil. The entire system consists of four parts: the test cell, the impulse generator and measurement component, the oil purifier system, and the discharge recording equipment.

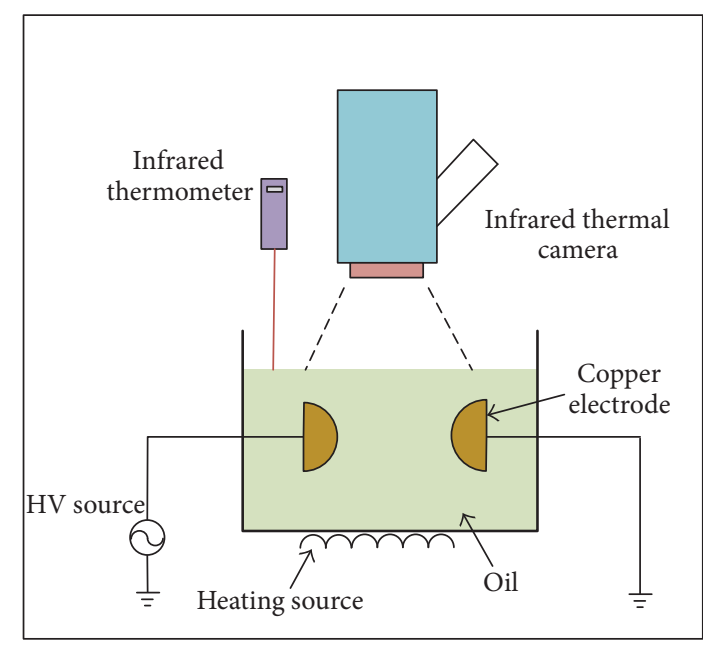

FIGURE 3: The schematic of the experimental setup for thermal response experiment.

2.3. Heat Transfer of Nano-Oil. The thermal conductivity of the nano-oil was measured using a TC3010L series liquid thermal conductivity tester, which had a maximum resolution of $0.0005 \mathrm{~W} / \mathrm{m} \mathrm{K}$ and accuracy of $0.5 \%$. The measurement was performed by unsteady instantaneous hot wire method, which can obtain accurate results in a short time. Prior to the test, at least $25 \mathrm{~mL}$ nano-oil was placed into the tester to avoid the effects of microwater and pollutants. During the experiments, the hot wire was heated for $2 \mathrm{~s}$ at a rate of $2^{\circ} \mathrm{C} / \mathrm{s}$. The hot wire simultaneously acted as a heat source and a temperature sensor by measuring the temperature changes surrounding the nano-oil and calculating the thermal conductivity. During the thermal conductivity test, the coefficient of thermal conductivity was first determined by injecting $25 \mathrm{~mL}$ of liquid and then using the hot wire for liquid heating. The heating time for $2 \mathrm{~s}$ and the heating rate were $2^{\circ} \mathrm{C} / \mathrm{s}$. Measuring a set of samples lasted for approximately $2-3 \mathrm{~min}$, and the software interface displayed the experimental data of thermal conductivity. Each test was repeated six times.

In view of the significant heat generated by the coil of electric current in a transformer, a thermal response experiment was conducted in this study. A $25^{\circ} \mathrm{C}$ and $55 \% \mathrm{RH}$ environment was maintained in the experiment. The heating and cooling processes were measured for pure oil, $0.1 \mathrm{vol} . \%$ nano-oil, 0.1 vol.\% nano-oil with $1 \mathrm{kV} / \mathrm{mm}$ DC, and $0.1 \mathrm{vol} . \%$ nano-oil with $1 \mathrm{kV} / \mathrm{mm} \mathrm{AC}$. The heating process ranged from $25^{\circ} \mathrm{C}$ to $80^{\circ} \mathrm{C}$, and the cooling process ranged from $80^{\circ} \mathrm{C}$ to $25^{\circ} \mathrm{C}$. The schematic of the experimental setup is shown in Figure 3.

\section{Results and Discussion}

3.1. Structural Characterization. The transmission electron microscopy (TEM) images of the exfoliated h-BN samples are presented in Figure 4. As shown, the size of the exfoliated h-BN nanoparticles was mostly irregular, and the length ranged from few hundreds of nanometers to one micrometer. 


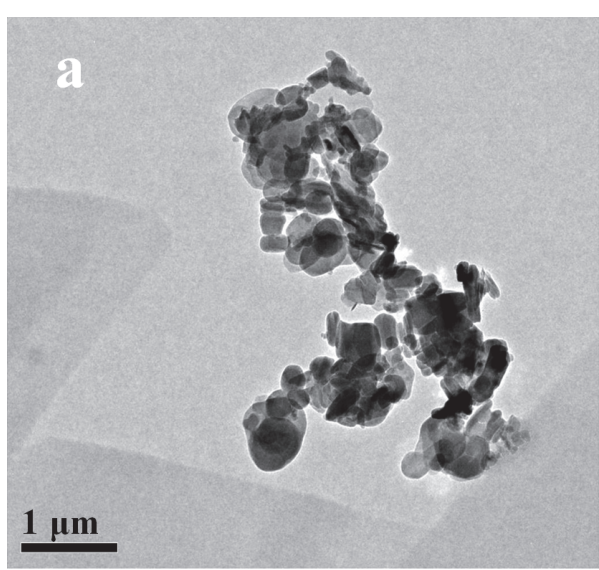

(a)

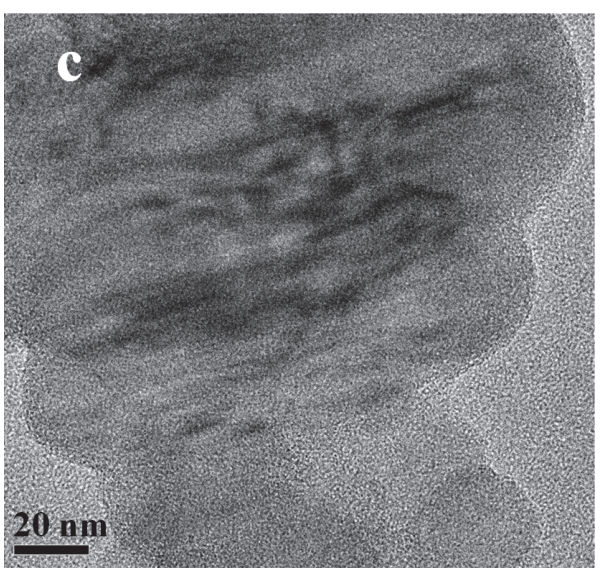

(c)

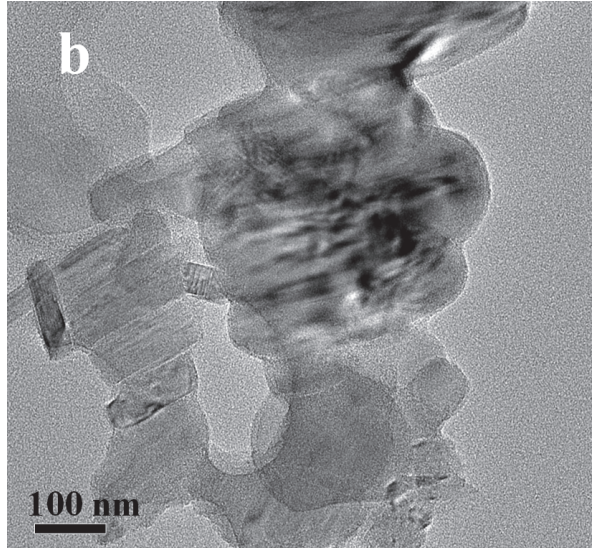

(b)

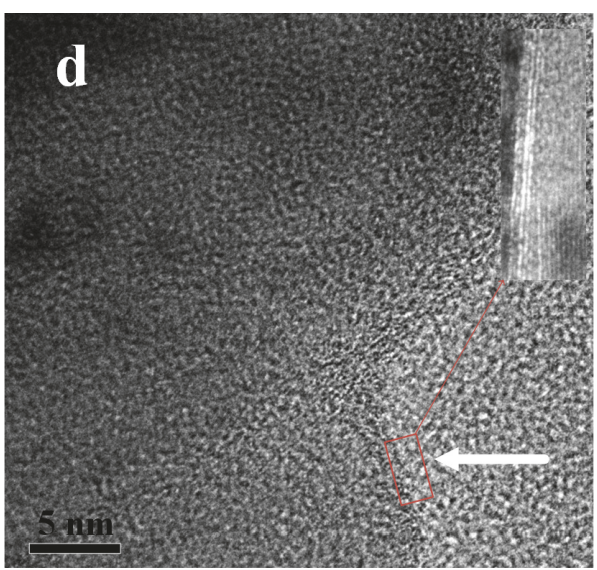

(d)

FIGURE 4: TEM images of exfoliated h-BN sample, (a), (b), (c), and (d) are all TEM images under different magnification, and the arrow in figure (d) is to magnify the edges of the nanosheet.

The h-BN nanosheets were few nanometers thick, which is expected to become even thinner as soon as possible. The thermal conductivity of the h-BN nanosheets is closely related to the number of layers [27]. Statistical analysis of 100 pieces of h-BN nanosheets (TEM images Figure 5(a)) revealed that the lengths of the exfoliated h-BN were mostly in the range of $300-700 \mu \mathrm{m}$. The X-ray diffraction (XRD) spectrum of the $\mathrm{h}-\mathrm{BN}$ powder indicated that the main prominent peak was located at $2 \theta=26.7^{\circ}$, which was the $\mathrm{h}$-BN lamellar direction corresponding to the (002) crystal face.

Figure 6 shows the nano-oil with different volume fractions of h-BN. The vegetable oil became milky after the nanoparticles were added. No particle sedimentation occurred in the nano-oil after $30 \mathrm{~d}$. The zeta potential of the nano-oil with BN nanoparticles, which determined the stability of the suspension, was measured by a Malvern ZS Nano $\mathrm{S}$ analyzer. The measurements were run at $10 \mathrm{~V}$ and $298 \mathrm{~K}$ for $50 \mathrm{~s}$. Each experiment was repeated five times to obtain the average value. The zeta potential of the h-BN nanooil with $0.1 \%$ volume concentration was $55 \mathrm{mV}$, indicating that the nanoparticles stabilized in vegetable oil.
3.2. Dielectric Properties. The test results of relative dielectric constant of nano-oil are shown in Figure 7(a). With the increase of concentration, the relative dielectric constant of nano-oil increases slowly. Its value increases from 3.08 (pure oil) to 3.11 (with 0.1 vol.\% nanoparticles) at $25^{\circ} \mathrm{C}$. Figure $7(\mathrm{~b})$ shows the resistivity and dissipation factor of nano-oil versus volume fractions at $25^{\circ} \mathrm{C}$ and $90^{\circ} \mathrm{C}$. The values of resistivity and dissipation factor of pure oil are $1.75 \times 10^{11} \Omega / \mathrm{m}$ and $0.046 \%$ at $25^{\circ} \mathrm{C}$, respectively. The values of resistivity and dissipation factor of nano-oil with 0.1 vol. $\%$ nanoparticles are $2.87 \times 10^{11} \Omega / \mathrm{m}$ and $0.033 \%$, which exhibit an increase of $63 \%$ and a decrease of $28 \%$ compared to those of the pure oil, respectively.

\subsection{Breakdown Voltage}

3.3.1. AC and DC Breakdown Voltage. The AC and DC breakdown voltage is a key indicator of electrical strength of the insulating oil; it indicates the high-voltage resistance in electrical equipment. Figure 8 shows the AC and DC breakdown voltage of nano-oil with different volume fractions at $25^{\circ} \mathrm{C}$ and $90^{\circ} \mathrm{C}$. The breakdown voltage was greater 


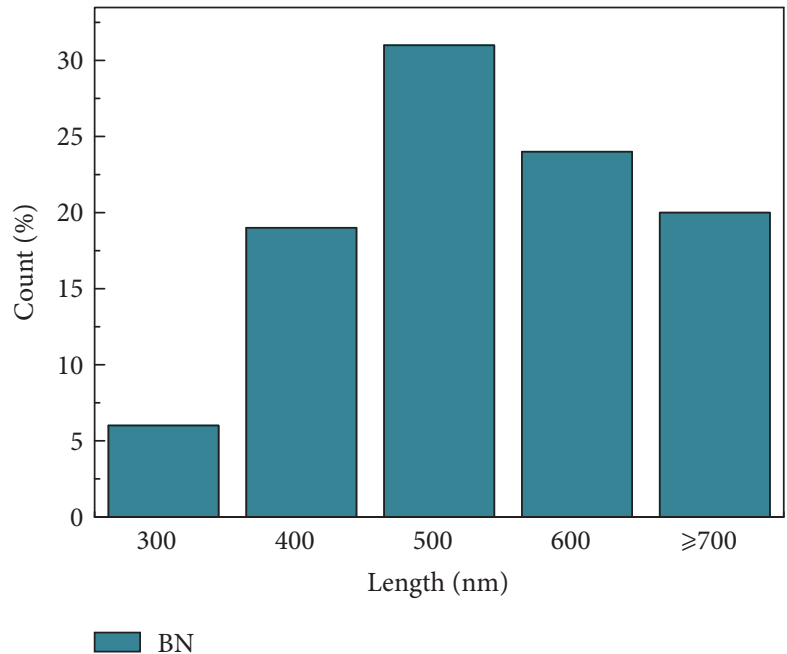

(a)

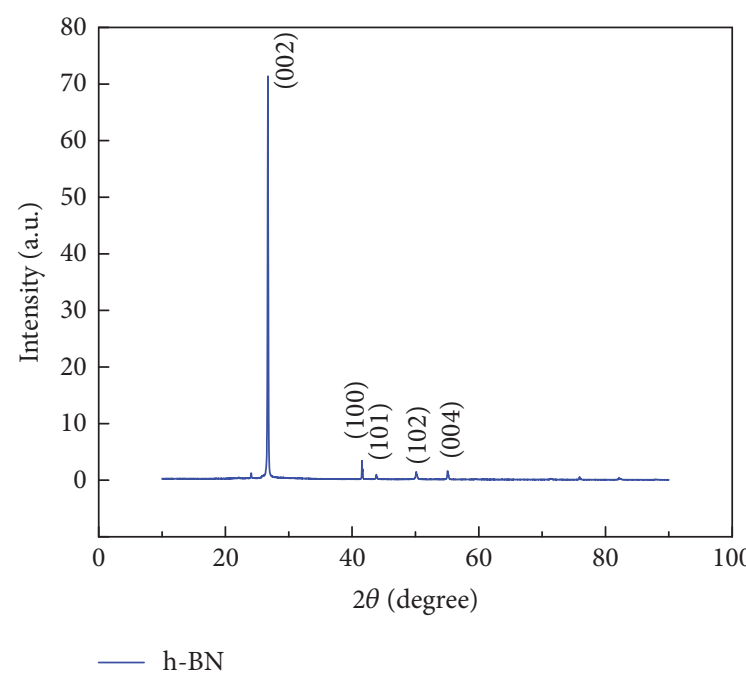

(b)

FIGURE 5: Length statistical analysis result with 100 pieces of h-BN nanoparticles (a) and XRD patterns of the h-BN nanosheets (b).

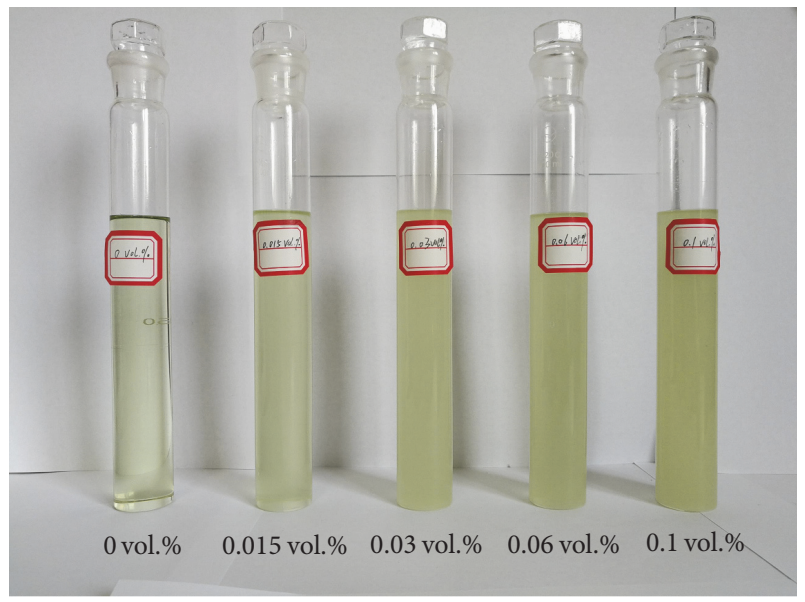

FIGURE 6: Photograph of pure oil and nano-oil with different volume fraction of h-BN.

at $90^{\circ} \mathrm{C}$ than at $25^{\circ} \mathrm{C}$ for both pure oil and nano-oil. The breakdown strength is closely related to the presence of gas, moisture, and impurities. The moisture concentration in the oil remained constant at different temperatures. However, the saturated water absorption capability of vegetable oil increased as the temperature increased, thereby reducing the relative moisture concentration. The breakdown voltage was significantly affected by the relative moisture because of the polarity sorting that occurs under an electric field, in which the electrons easily travel along a neatly arranged bridge to the discharge channel. Consequently, the breakdown voltage was increased.

The AC breakdown voltage of the $\mathrm{h}-\mathrm{BN}$ nano-oil was stable, and it increased as the nanoparticle volume increased in Figure $8(\mathrm{a})$. When the volume concentration was $0.1 \%$, the breakdown voltage increased by $18 \%$ at $25^{\circ} \mathrm{C}$ and $15 \%$ at $90^{\circ} \mathrm{C}$. The DC breakdown voltage of nano-oil performs similar tendency as AC breakdown voltage in Figure 8(b). The h-BN nanoparticles exhibited high insulation with a wide band gap (approximately 5.5 6.4 eV), which enhanced the breakdown voltage of the vegetable oil. Moreover, an electric charge was generated on the surface of the nanoparticle because of the polarization under the electric field. These polarized charges generated the electric field, which changed the original electric field. A "trapping" was formed near the nanoparticles, thereby enhancing the breakdown voltage [28].

3.3.2. Lightning Impulse Breakdown Voltage. The characteristics of the impulse breakdown voltage are key performance indicators of insulating materials, particularly for oil-paper insulation. Figure 9 shows the positive and negative lightning impulse breakdown voltages of nano-oil with different volume fractions. As the volume fraction of the nanoparticles increased, the lightning impulse breakdown voltage also increased. The average positive lightning impulse breakdown voltage of the nano-oil with $0.1 \mathrm{vol} . \%$ was $60 \mathrm{kV}$, which was $23 \%$ greater than that of pure vegetable oil. The average negative lightning impulse breakdown voltage was $95 \mathrm{kV}$, which was $10 \%$ greater than that of pure vegetable oil.

Figure 10 shows the lightning breakdown time of pure oil and nano-oil with different volume fractions of nanoparticles. The positive and negative lightning impulse times of nano-oil were significantly higher than those of pure vegetable oil, and the maximum value was increased by $22.0 \%$ and $28.8 \%$ for the positive and negative cases, respectively. The rate of average streamer can be expressed as follows:

$$
\bar{v}=\frac{d}{t}
$$

where $d$ is the gap distance of electrodes $(1.5 \mathrm{~cm})$ and $t$ is the breakdown time $(\mu \mathrm{s})$. As calculated by formula (2), the maximum streamer rate of nano-oil was 1.38 and $1.04 \mathrm{~km} / \mathrm{s}$ 


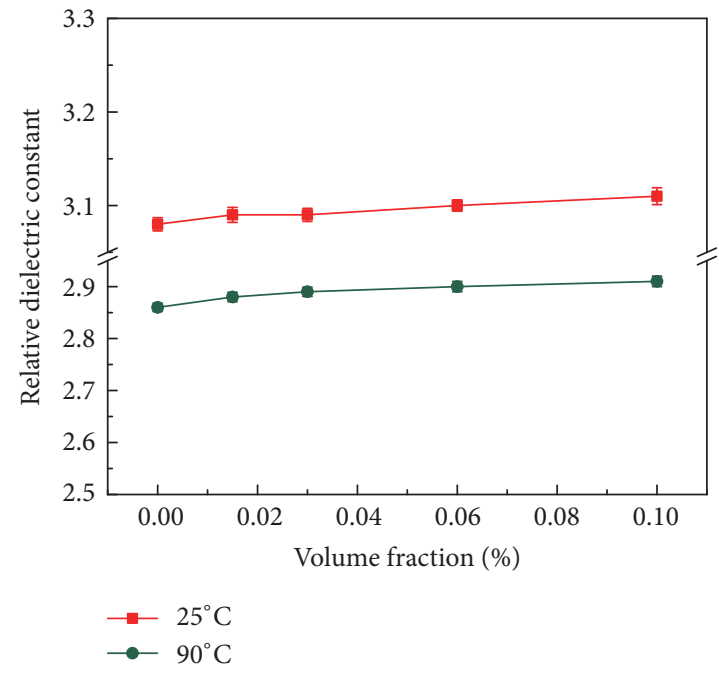

(a)

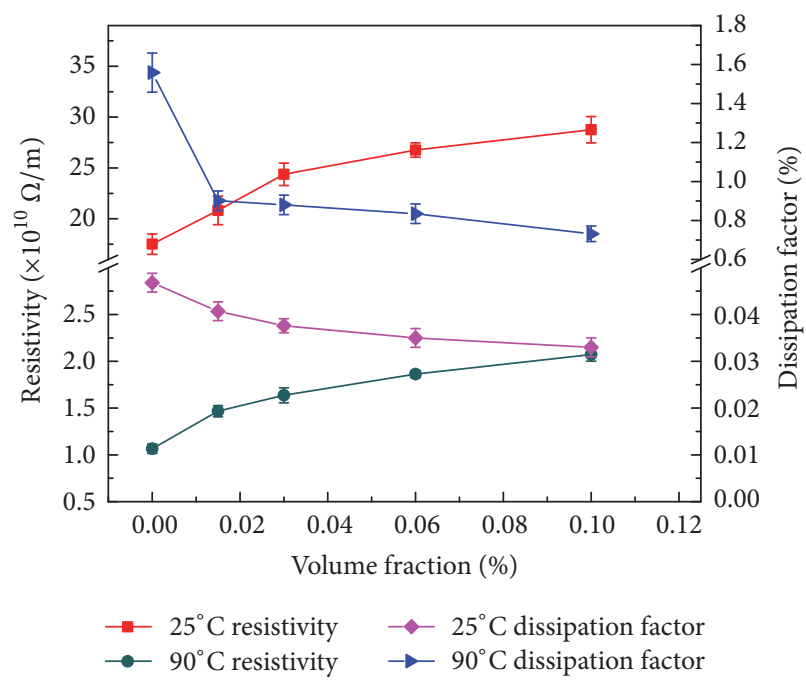

(b)

FiguRE 7: Relative dielectric constant (a) and resistivity and dissipation factor (b) of nano-oil with different volume fractions at $25^{\circ} \mathrm{C}$ and $90^{\circ} \mathrm{C}$.

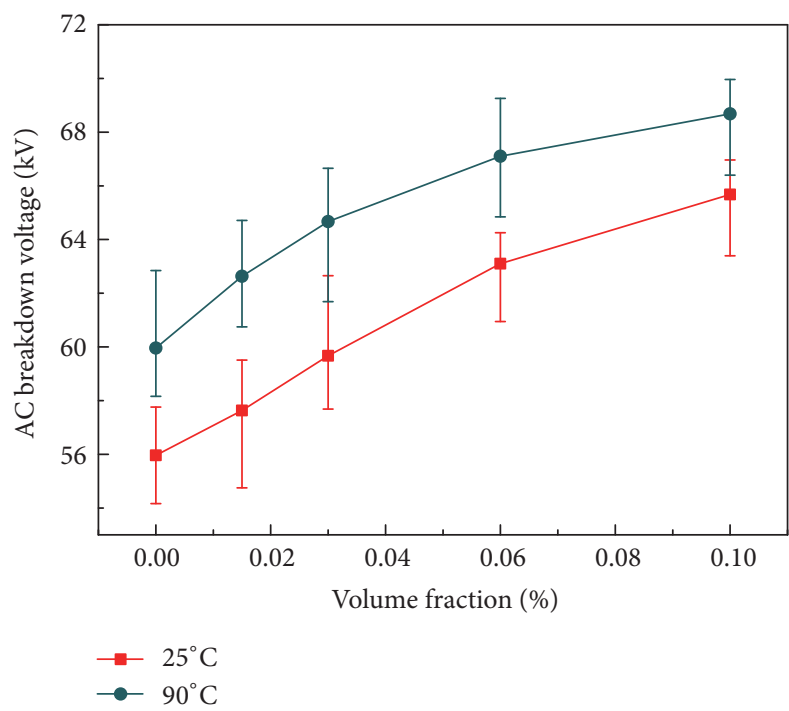

(a)

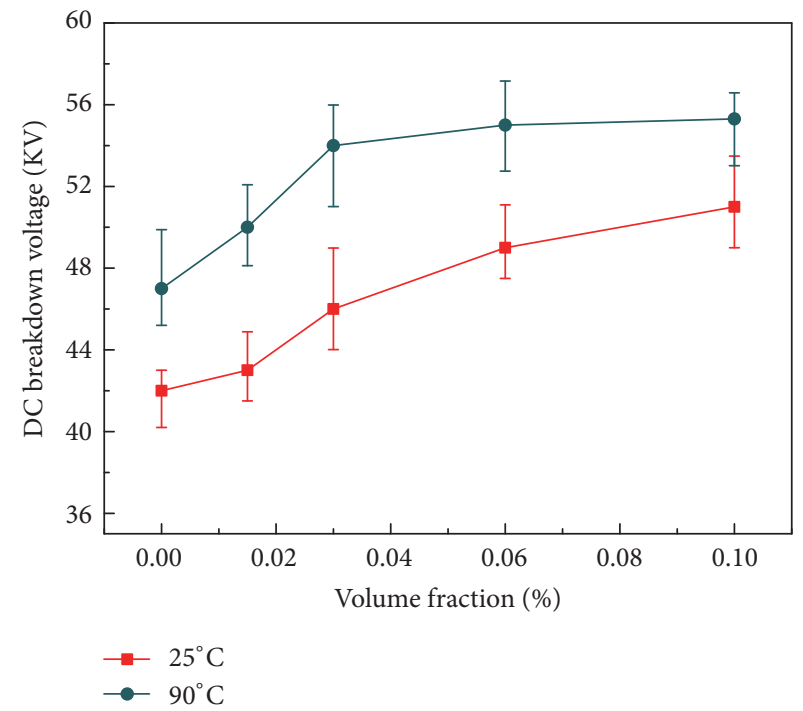

(b)

FIGURE 8: AC (a) and DC (b) breakdown voltage of nano-oil with different volume fractions at $25^{\circ} \mathrm{C}$ and $90^{\circ} \mathrm{C}$.

for the positive and negative lightning impulses, respectively. However, the positive and negative lightning impulse streamer rates of the pure vegetable oil were 1.5 and $1.3 \mathrm{~km} / \mathrm{s}$, respectively. These results indicate that the nanoparticles can effectively retard the development of streamers in the insulating oil.

The increase in positive impulse breakdown voltage of the nano-oil was larger than the negative one. This phenomenon can be explained by space charge theory $[23,29]$. In the positive polarity model (Figure 11), some electrons near the positive-electrode were captured by nanoparticles. These nanoparticles, which become negative ions electrons, caused the additional electric field with positive charge behind in
Figure 11(b). These space charges reinforced the electric field near the positive pole but also weakened the electric field with other electrodes. When the voltage increased, discharge was not easily developed, thus preventing a breakdown of the entire gap breakdown. By contrast, in the negative polarity model, the space electric field generated by the nanometer anion enhanced the electric field near the needle electrode and reduced only the electric field away from the needle electrode. Therefore, the increase in the negative lightning breakdown was less than that in the positive one.

The images of the streamer discharge formation are shown in Figure 12. The streamer discharge was initiated and then gradually developed as the applied voltage increased. 


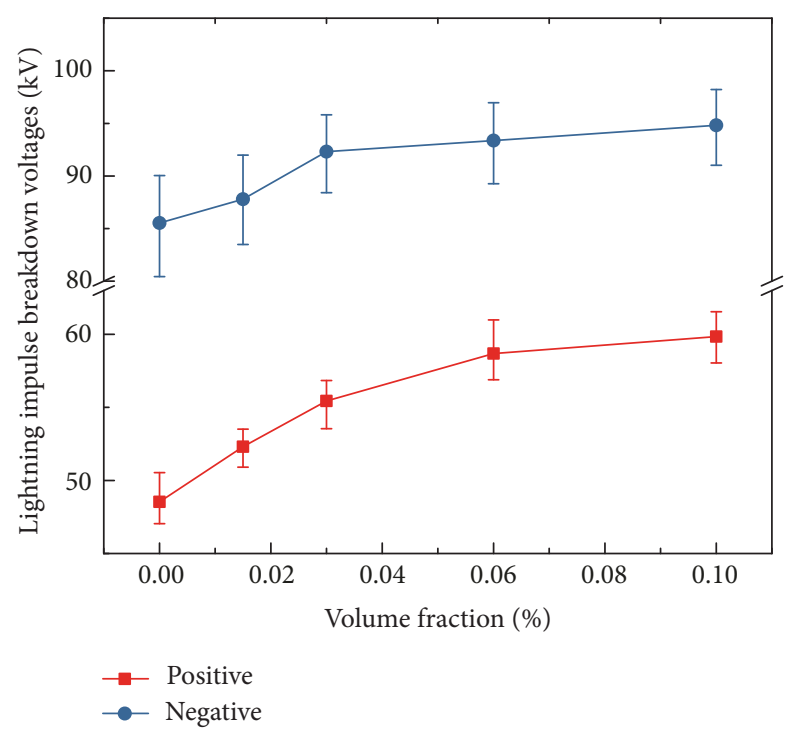

FIgURE 9: Positive and negative lightning impulse breakdown voltages of nano-oil with different volume fractions.

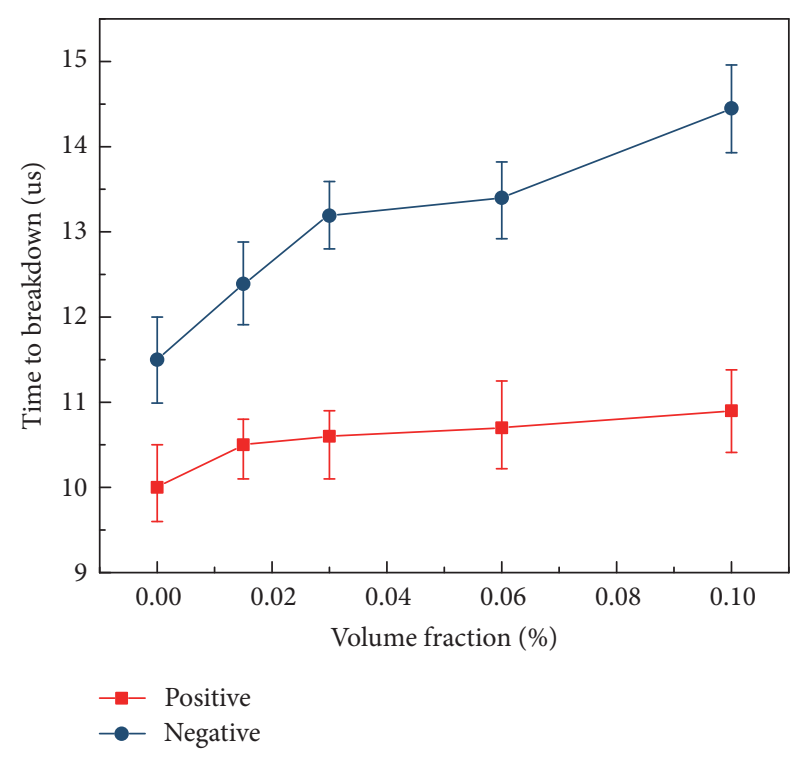

FIGURE 10: Positive and negative time of lightning impulse nano-oil varying with volume fraction.

The streamer propagation images of pure oil (Figure 12(a)(6)) and nano-oil (Figure 12(b)(6)) were captured at $40 \mathrm{kV}$. More branches were observed for nano-oil than for pure oil. Given the greater number of branches at the streamer heads, the electric field of nano-oil was less distorted than that of pure oil because of the shielding effect. Consequently, the streamer was suppressed, thereby decreasing the propagation length and velocity $[29,30]$. These results indicated that the $h$ $\mathrm{BN}$ inhibited the steamer propagation and enhanced the breakdown voltage.

As demonstrated in Figures 12(a)(1-5) and 12(b)(1-5), the development process of the lightning impulse mechanism of the nanovegetable oil is similar to that of the vegetable oil. The process started at the initial state of the streamer. When the electric field gradually increased, liquid molecules appeared, and bubble ionization occurred near the needle tip. The ionization region expanded as the applied voltage increased, ultimately closing the area near the needle tip to form the streamer and the corona. Consequently, a smallscale streamer body was formed. If the applied voltage was further enhanced, the streamer body would continue growing around the core, that is, the needle top. Then, the streamer quickly spread to the direction of the ground electrode after initiation, the shape of which was converted into a branch or a long filament state that diverged outwardly from the needle tip by a small-scale dispersion or a filament state distribution near the tip. The streamer morphology grew along the electric field line and accelerated the plate electrode as the voltage was increased. In addition, the transmission of the streamer was limited by the electric field strength, the dielectric liquid, and the streamer resistivity, causing the streamer to reach a specific length without further development. Therefore, if the voltage was insufficient to cause a breakdown, the streamer would disappear after reaching a certain length. In most cases, if the applied voltage reached the breakdown voltage, the streamer would jump to the main charge channel at a very high speed after reaching a specific length. However, nano-oil requires a higher voltage to form the charge channel for breakdown. Therefore, the addition of nanoparticles can effectively improve the electrical characteristics of the liquid dielectric by improving the breakdown voltage and inhibiting the streamer development, implying the suitability of nanoparticles in transformers.

\subsection{Heat Transfer of Nano-Oil}

3.4.1. Thermal Conductivity of Nano-Oil. In power transformers, the insulating liquid dielectric plays a role not only in insulation but also in heat dissipation. The internal heat source of the oil-immersed transformer was mainly generated by core losses and winding losses, and the losses were transformed into heat, resulting in the increased temperature of the oil [31]. The high temperature of the inner part of the transformer accelerated the aging of the insulating materials and diminished the operation life of the transformer. In addition, an electric field was created inside the transformer, although the effect of this electric field on the heat transfer of nano-oil was unknown. The improved insulation and heat transfer performance are beneficial to the miniaturization of high-power transformers.

The thermal conductivity of the nano-oil changed with the nanoparticle volume fraction as shown in Figure 13. Nanoparticles addition was found beneficial to improving the fluid thermal conductivity. A higher temperature of the nano-oil corresponded to a larger increase in the thermal conductivity. As shown in Figure 13, the thermal conductivity of nano-oil with 0.1 vol.\% nanoparticles increased by $11.9 \%$ at $25^{\circ} \mathrm{C}\left(0.1875 .6 \mathrm{WK}^{-1} \mathrm{~m}^{-1}\right.$ versus $0.167 \mathrm{WK}^{-1} \mathrm{~m}^{-1}$ of pure vegetable oil $)$ and by $14 \%$ at $90^{\circ} \mathrm{C}\left(0.185 \mathrm{WK}^{-1} \mathrm{~m}^{-1}\right.$ versus $0.161 \mathrm{WK}^{-1} \mathrm{~m}^{-1}$ of pure vegetable oil). The increased thermal conductivity of the nano-oil was due to not only the high 


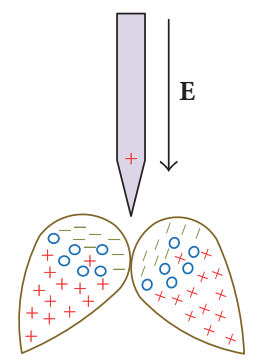

(a)

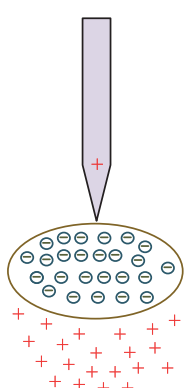

(b)

FIGURE 11: Space charge build-up in positive needle-sphere gap.
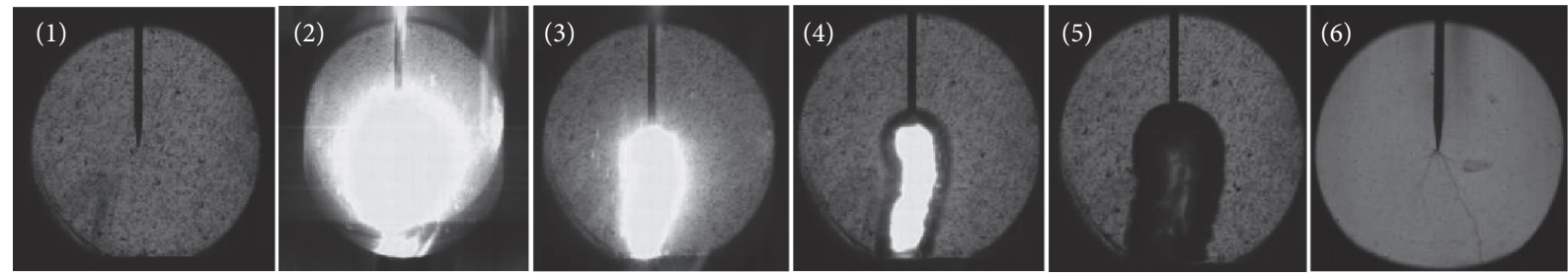

(a)
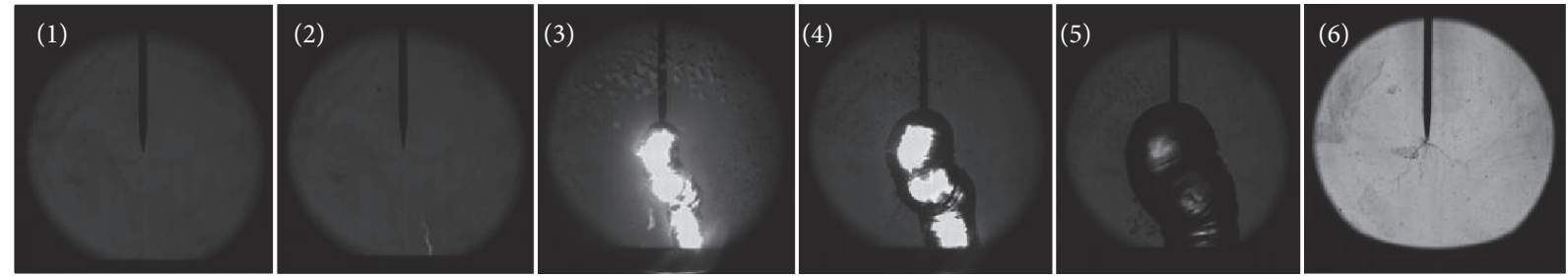

(b)

Figure 12: Positive streamer propagation images for pure oil (a) and nano-oil (b) with $0.03 \%$ vol. nanoparticles. Figures (a)(1-5) and (b)(1-5) are process of breakdown with 20 us interval. The breakdown time of nano-oil is larger than pure oil. Figures (a)(6) and (b)(6) are the streamer images of prebreakdown under applied voltage of $40 \mathrm{kV}$. Compared to pure oil, the length of streamer of nano-oil is shorter and streamer with greater number of branches.

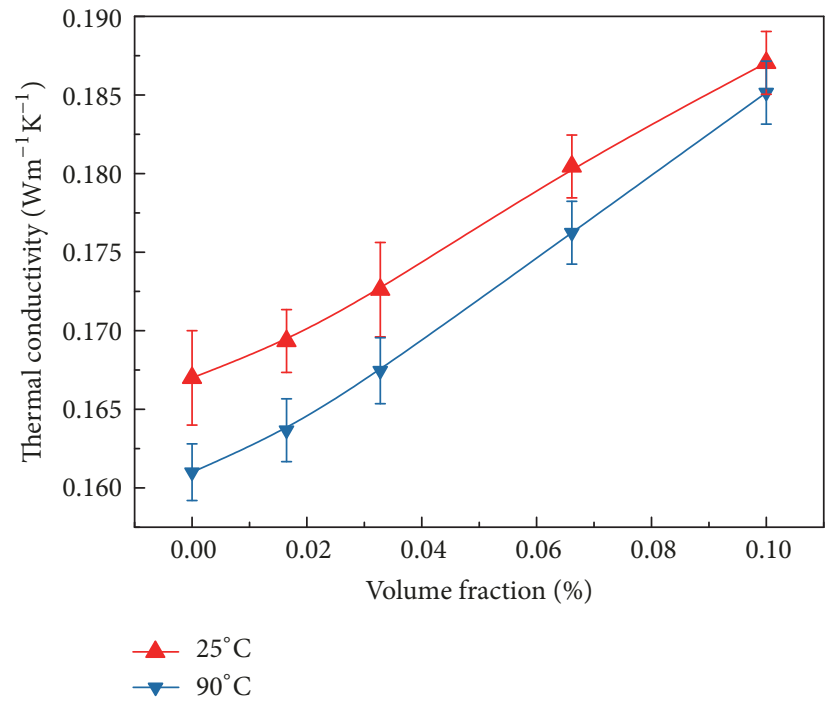

FIGURE 13: The thermal conductivity of nano-oil varying with volume fraction at $25^{\circ} \mathrm{C}$ and $90^{\circ} \mathrm{C}$. thermal conductivity of $\mathrm{h}-\mathrm{BN}\left(300 \mathrm{Wm}^{-1} \mathrm{~K}^{-1}\right)$ but also the large specific surface area.

For a solid-liquid mixture, if the solid particles are dispersed in the liquid without aggregation, then the thermal conductivity of a liquid-solid mixture can be obtained based on the volume fraction of spherical solid particles in the liquid Maxwell model as follows [32]:

$$
\frac{k_{\text {eff }}}{k_{f}}=\frac{k_{p}+2 k_{f}-2 \varphi\left(k_{f}-k_{p}\right)}{k_{p}+2 k_{f}+\varphi\left(k_{f}-k_{p}\right)},
$$

where $k_{\text {eff }}$ is the thermal conductivity of the solid-liquid mixture, $k_{p}$ is the thermal conductivity of the nanoparticles, and $k_{f}$ is the thermal conductivity of the nanofluids. However, the Maxwell model does not consider the interaction between the nanoparticles and their shapes, making it suitable only for liquid-solid mixtures in which the solid and the liquid have similar volume fractions. The liquid molecules are adsorbed on the surface of the nanoparticles, called the interfacial layer, which was a heat exchange bridge between solid materials 


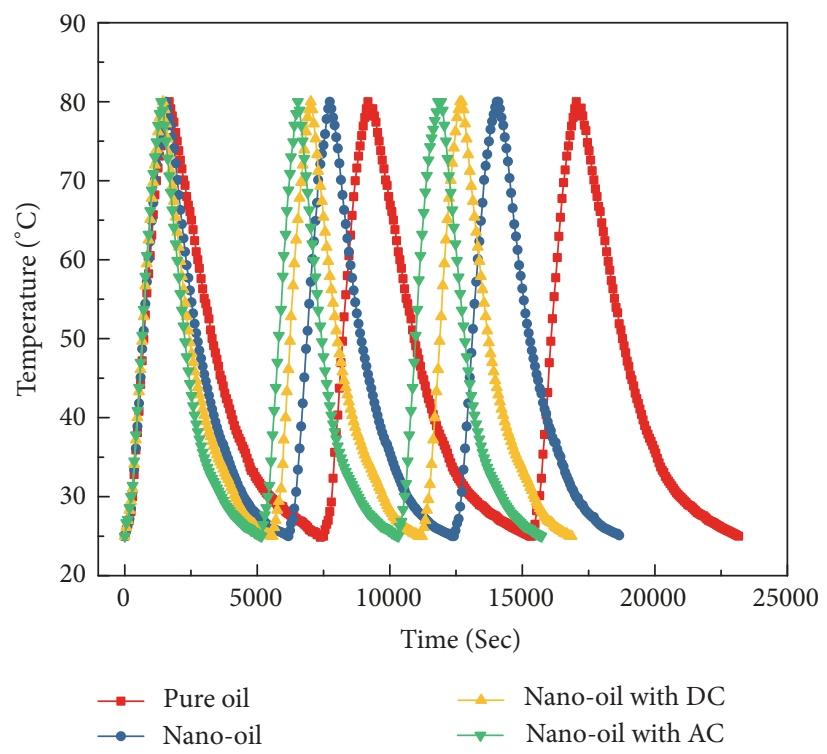

FIGURE 14: Heating and cooling responses of the vegetable oil and nano-oil under DC and AC electric fields.

and base fluids [33]. In the interfacial layers of solid-liquid mixtures, the degree of ordering of the liquid molecules near the solid surface was higher than that of the liquid molecules. Its thermal conductivity was between that of solid and liquid particles, because the liquid layer was highly ordered and closer to the solid. The adsorption layer enhanced the effective volume fraction of the nanoparticles and in turn the thermal conductivity of the nano-oil. Brownian motion caused particles to disperse in the base fluid for disordered movement. The passing heat between colliding particles may increase the effective thermal conductivity of the nano-oil. In particular, a higher temperature corresponded to a more intense Brownian motion. Thus, the enhancement in the thermal conductivity of the nano-oil was more apparent at $90^{\circ} \mathrm{C}$ than at $25^{\circ} \mathrm{C}$. In addition, as the nanoparticle volume fraction was increased in the vegetable oil, the nanoparticle distance was decreased, thereby increasing the probability of contact among the nanoparticles. Consequently, thermal conduction channels were formed, which may increase the thermal conductivity due to the percolation mechanism.

3.4.2. Heating and Cooling Responses of Nano-Oil. The heating and cooling responses can more intuitively illustrate the heat transfer efficiency of liquid dielectrics. Figure 14 shows the thermal responses of vegetable oil and nano-oil under DC and $\mathrm{AC}$ electric fields for cycling up to $80^{\circ} \mathrm{C}$ for three times, and the infrared thermal images are shown in Figure 15 at first heating and cooling responses. As shown, the nano-oil, given its high thermal conductivity, exhibited faster heating and cooling than pure oil. As the temperature approached room temperature, the temperature of the nano-oil gradually declined. However, the nano-oil with an electric field (either DC or AC) presented an increased heat transform, and the nano-oil with an AC electric field promoted faster cooling faster than that with a DC electric field. According to the results in Figure 14, repeated heating and cooling test are well repeatability. Compared to pure oil, each heating and cooling cycle time of nano-oil, nano-oil with DC, and nanooil with AC on average decreased 19.4\%, 27.2\%, and 32.1\%, respectively.

The h-BN distribution in the vegetable oil was irregular without an electric field. However, the h-BN is oriented under the force of the electric field. The main diffraction peak of boron nitride was $2 \theta=26.7^{\circ}$, which corresponded to the (002) crystal plane, that is, the h-BN lamellar orientation. The h-BN under an electric field is oriented in this direction to form the network of heat transfer (the diagram in Figure 16). As shown in Figure 14, the nano-oil has a faster thermal response rate under an AC electric field than a DC electric field. Given that more thermal chains are formed, the chain length and tightness were greater under the electric field. When the thermal network was formed with the heat flow parallel to the interior of the nano-oil, the heat flux was transmitted through the formed network chain, because the thermal resistance of the nanoparticles was substantially smaller than that of the vegetable oil. Thus, the thermal resistance of the nano-oil was reduced, and the thermal conductivity was improved.

\section{Conclusion}

In summary, the following conclusions were drawn based on the experimental and analytical results. (i) The h-BN nanosheets were successfully exfoliated in isopropanol solution and stably dispersed in vegetable oil. (ii) The nanoparticles increased resistivity and decreased dissipation factor of vegetable oil. AC and DC breakdown increased by $18 \%$ and $19 \%$ at $25^{\circ} \mathrm{C}$ as the nanoparticles volume increased to $0.1 \mathrm{vol} . \%$, respectively. (iii) The average positive and negative lightning impulse breakdown voltages of nano-oil with 0.1 vol. $\%$ were $23 \%$ and $10 \%$ greater than that of pure vegetable oil, respectively. (iv) The thermal conductivity of the nano-oil was greatly enhanced (14\%) with a low volume 


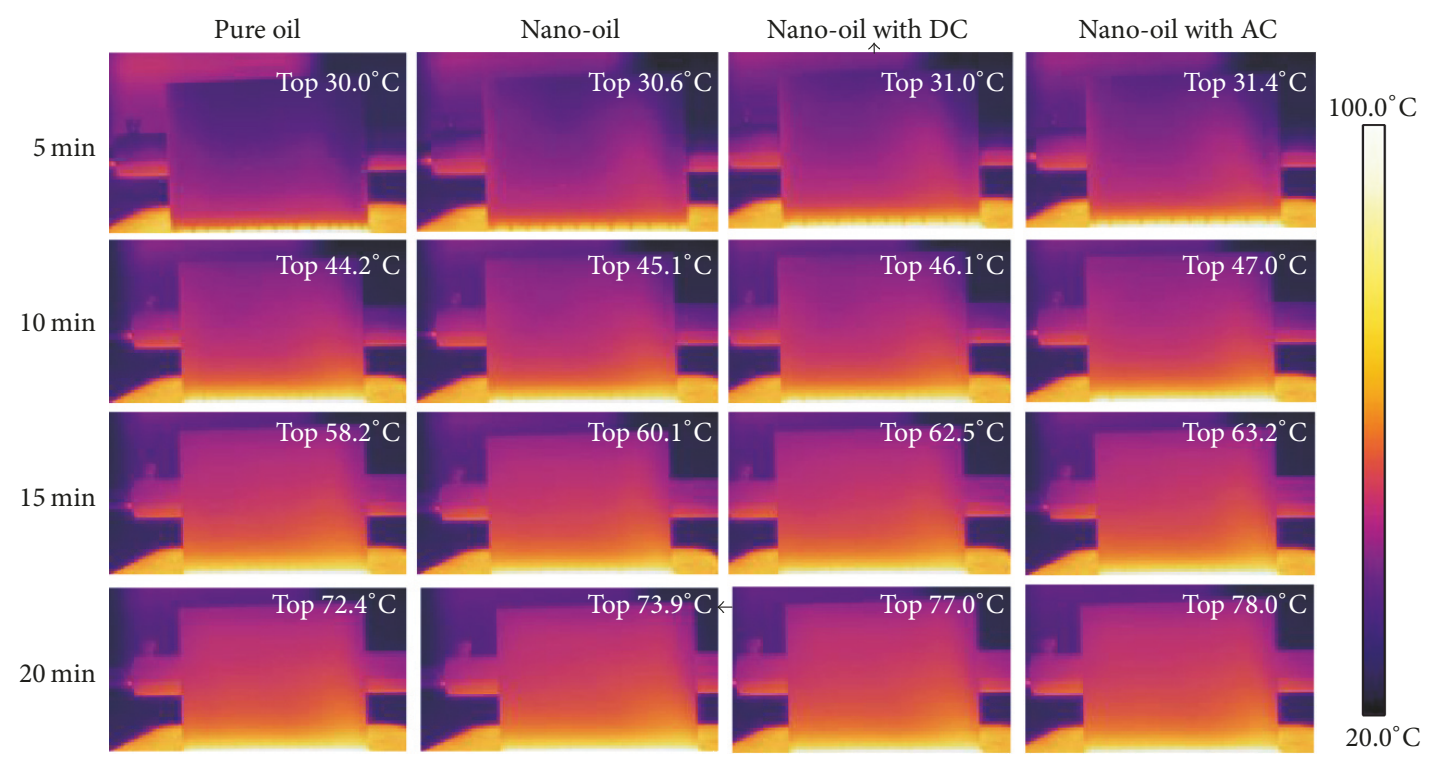

(a)

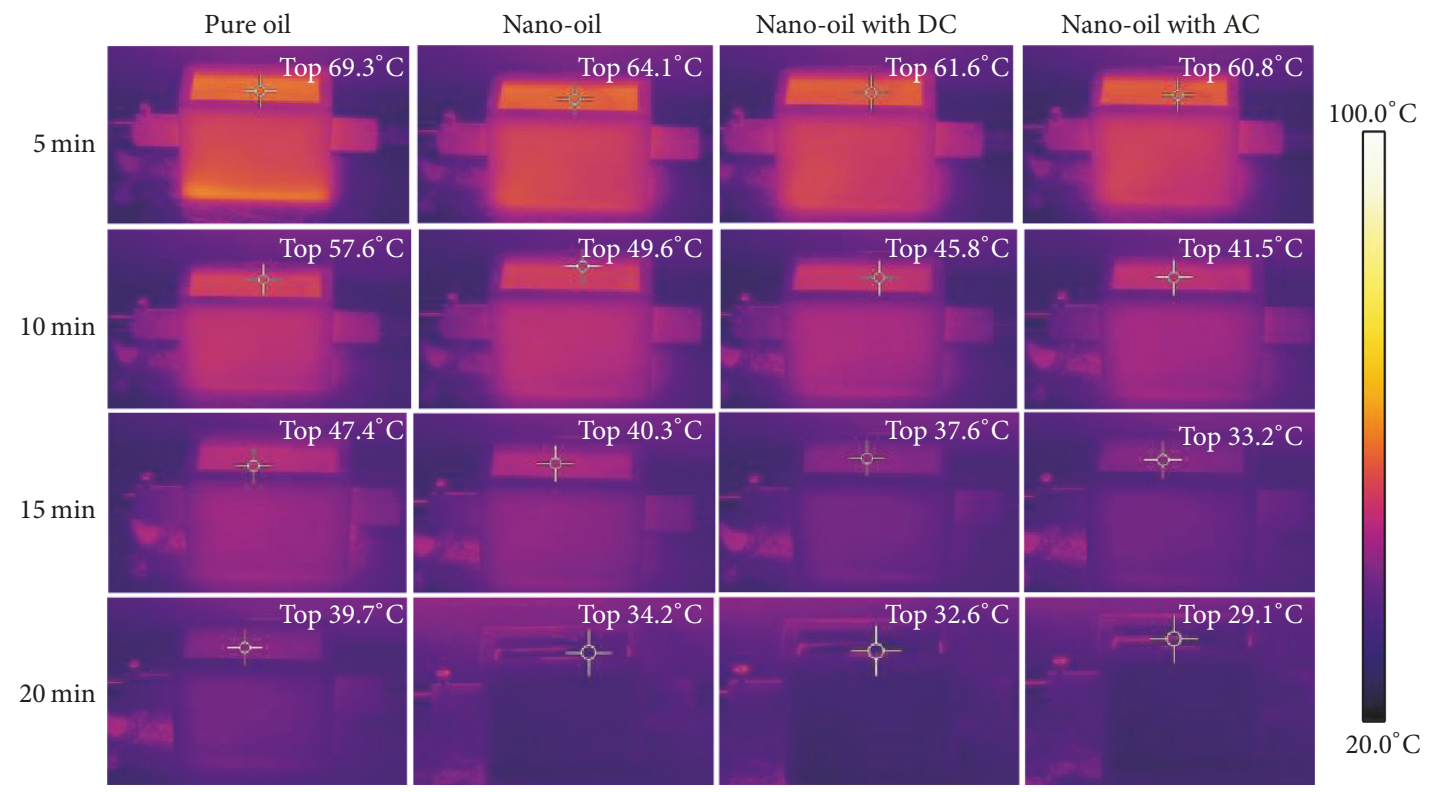

(b)

FIGURE 15: Infrared thermal images of nano-oil for heating (a) and cooling (b).

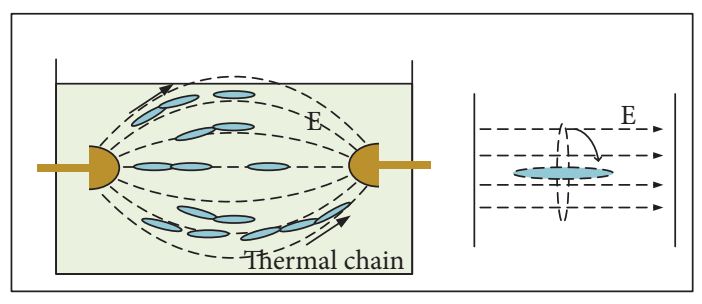

$\Longleftrightarrow$ h-BN

FIgURE 16: The diagram of thermal chain formed under electrical field. 
fraction. The presence of an electric field was advantageous to the heat transfer of nano-oil-based h-BN fillers. Such improvements of insulation and heat transfer are beneficial to the miniaturization of high-power transformers.

\section{Conflicts of Interest}

The authors declare that they have no conflicts of interest.

\section{Acknowledgments}

The authors acknowledge the support from the National Natural Science Foundation of China (Grants nos. 51425702 and 51377176) and the 111 Project of the Ministry of Education, China (B08036).

\section{References}

[1] Y. Guangbin, G. Dejun, C. Juhui et al., "Experimental Research on Heat Transfer Characteristics of $\mathrm{CuO}$ Nanofluid in Adiabatic Condition," Journal of Nanomaterials, vol. 2016, Article ID 3693249, 2016.

[2] Y.-H. Hung and H.-J. Gu, "Multiwalled carbon nanotube nanofluids used for heat dissipation in hybrid green energy systems," Journal of Nanomaterials, vol. 2014, Article ID 196074, 2014.

[3] B. Du, J. Li, F. Wang, W. Yao, and S. Yao, "Influence of Monodisperse $\mathrm{Fe}_{3} \mathrm{O}_{4}$ Nanoparticle Size on Electrical Properties of Vegetable Oil-Based Nanofluids," Journal of Nanomaterials, vol. 2015, Article ID 560352, pp. 1-9, 2015.

[4] M. Jama, T. Singh, S. M. Gamaleldin et al., "Critical review on nanofluids: preparation, characterization, and applications," Journal of Nanomaterials, vol. 2016, Article ID 6717624, 22 pages, 2016.

[5] M. Sheikholeslami, T. Hayat, and A. Alsaedi, "MHD free convection of Al2O3-water nanofluid considering thermal radiation: a numerical study," International Journal of Heat and Mass Transfer, vol. 96, pp. 513-524, 2016.

[6] G. D. Peppas, A. Bakandritsos, V. P. Charalampakos et al., "Ultrastable Natural Ester-Based Nanofluids for High Voltage Insulation Applications," ACS Applied Materials \& Interfaces, vol. 8, no. 38, pp. 25202-25209, 2016.

[7] N. Bhalla and P. Estrela, "Smart micro/nano-robotic systems for gene delivery," Current Topics in Medicinal Chemistry, vol. 17, 2017.

[8] R. Singh, G. S. Sandhu, R. Penna, and I. Farina, "Investigations for thermal and electrical conductivity of ABS-graphene blended prototypes," Materials, vol. 10, no. 8, article no. 881, 2017.

[9] Q. A. Pankhurst, J. Connolly, S. K. Jones, and J. Dobson, "Applications of magnetic nanoparticles in biomedicine," Journal of Physics D: Applied Physics, vol. 36, no. 13, pp. R167-R181, 2003.

[10] S. Peng, L. Li, J. Kong Yoong Lee et al., "Electrospun carbon nanofibers and their hybrid composites as advanced materials for energy conversion and storage," Nano Energy, vol. 22, pp. 361-395, 2016.

[11] K. Bandara, C. Ekanayake, T. Saha, and H. Ma, "Performance of natural ester as a transformer oil in moisture-rich environments," Energies, vol. 9, no. 4, article no. 258, 2016.

[12] R. S. Khedkar, N. Shrivastava, S. S. Sonawane, and K. L. Wasewar, "Experimental investigations and theoretical determination of thermal conductivity and viscosity of $\mathrm{TiO} 2$-ethylene glycol nanofluid," International Communications in Heat and Mass Transfer, vol. 73, pp. 54-61, 2016.

[13] J. H. Lee, D. H. Kam, and Y. H. Jeong, "The effect of nanofluid stability on critical heat flux using magnetite-water nanofluids," Nuclear Engineering and Design, vol. 292, pp. 187-192, 2015.

[14] M. Sanchez-Dominguez and C. Rodríguez-Abreu, Nanocolloids: A Meeting Point for Scientists and Technologists, 2016.

[15] C. A. S. Batista, R. G. Larson, and N. A. Kotov, "Nonadditivity of nanoparticle interactions," Science, vol. 350, no. 6257, Article ID 1242477, 2015.

[16] W. B. Russel, D. A. Saville, and W. R. Schowalter, Colloidal Dispersions, Cambridge University Press, 1989.

[17] J. Rao and D. J. McClements, "Stabilization of phase inversion temperature nanoemulsions by surfactant displacement," Journal of Agricultural and Food Chemistry, vol. 58, no. 11, pp. 70597066, 2010.

[18] Y. Lv, M. Rafiq, C. Li, and B. Shan, "Study of Dielectric Breakdown Performance of Transformer Oil Based Magnetic Nanofluids," Energies, vol. 10, no. 7, p. 1025, 2017.

[19] H. Jin, T. Andritsch, I. A. Tsekmes, R. Kochetov, P. H. F. Morshuis, and J. J. Smit, "Properties of mineral oil based silica nanofluids," IEEE Transactions on Dielectrics and Electrical Insulation, vol. 21, no. 3, pp. 1100-1108, 2014.

[20] Y. Du, Y. Lv, C. Li et al., "Effect of electron shallow trap on breakdown performance of transformer oil-based nanofluids," Journal of Applied Physics, vol. 110, no. 10, Article ID 104104, 2011.

[21] D.-E. A. Mansour, A. M. Elsaeed, and M. A. Izzularab, “The role of interfacial zone in dielectric properties of transformer oil-based nanofluids," IEEE Transactions on Dielectrics and Electrical Insulation, vol. 23, no. 6, pp. 3364-3372, 2016.

[22] A. Beroual, U. Khaled, P. S. M. Noah, and H. Sitorus, "Comparative study of breakdown voltage of mineral, synthetic and natural oils and based mineral oil mixtures under AC and DC voltages," Energies, vol. 10, no. 4, article 511, 2017.

[23] J. Li, Z. Zhang, P. Zou, B. Du, and R. Liao, "Lightning impulse breakdown characteristics and electrodynamic process of insulating vegetable oil-based nanofluid," Modern Physics Letters B, vol. 26, no. 15, Article ID 1250095, 13 pages, 2012.

[24] J. A. Eastman, S. U. S. Choi, S. Li, W. Yu, and L. J. Thompson, "Anomalously increased effective thermal conductivities of ethylene glycol-based nanofluids containing copper nanoparticles," Applied Physics Letters, vol. 78, no. 6, pp. 718-720, 2001.

[25] R. Zheng, J. Gao, J. Wang et al., “Thermal percolation in stable graphite suspensions," Nano Letters, vol. 12, no. 1, pp. 188-192, 2012.

[26] E.-O. Ettefaghi, H. Ahmadi, A. Rashidi, A. Nouralishahi, and S. S. Mohtasebi, "Preparation and thermal properties of oil-based nanofluid from multi-walled carbon nanotubes and engine oil as nano-lubricant," International Communications in Heat and Mass Transfer, vol. 46, no. 8, pp. 142-147, 2013.

[27] I. Jo, M. T. Pettes, J. Kim et al., "Thermal conductivity and phonon transport in suspended few-layer hexagonal boron nitride," Nano Letters, vol. 13, no. 2, pp. 550-554, 2013.

[28] J. Li, B. Du, F. Wang, W. Yao, and S. Yao, “The effect of nanoparticle surfactant polarization on trapping depth of vegetable insulating oil-based nanofluids," Physics Letters A, vol. 380, no. 4, pp. 604-608, 2016.

[29] N. V. Dung, H. K. Høidalen, D. Linhjell, L. E. Lundgaard, and M. Unge, "Effects of reduced pressure and additives on streamers in white oil in long point-plane gap," Journal of Physics D: Applied Physics, vol. 46, no. 25, Article ID 255501, 2013. 
[30] Y. Lv, Y. Ge, Q. Du et al., “ Fractal Analysis of Positive Streamer Patterns in Transformer Oil-Based TiO ", IEEE Transactions on Plasma Sciences, vol. 45, no. 7, pp. 1704-1709, 2017.

[31] W. H. Tang, Q. H. Wu, and Z. J. Richardson, "Equivalent heat circuit based power transformer thermal model," IEE Proceedings Electric Power Applications, vol. 149, no. 2, pp. 8792, 2002.

[32] M. J. Clerk, "A treatise on electricity and magnetism," Nature, vol. 7, no. 182, pp. 478-480, 1904.

[33] S. Cho, K. Kikuchi, and A. Kawasaki, "On the role of amorphous intergranular and interfacial layers in the thermal conductivity of a multi-walled carbon nanotube-copper matrix composite," Acta Materialia, vol. 60, no. 2, pp. 726-736, 2012. 


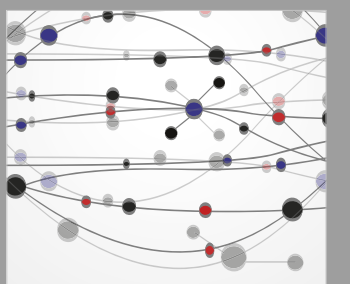

The Scientific World Journal
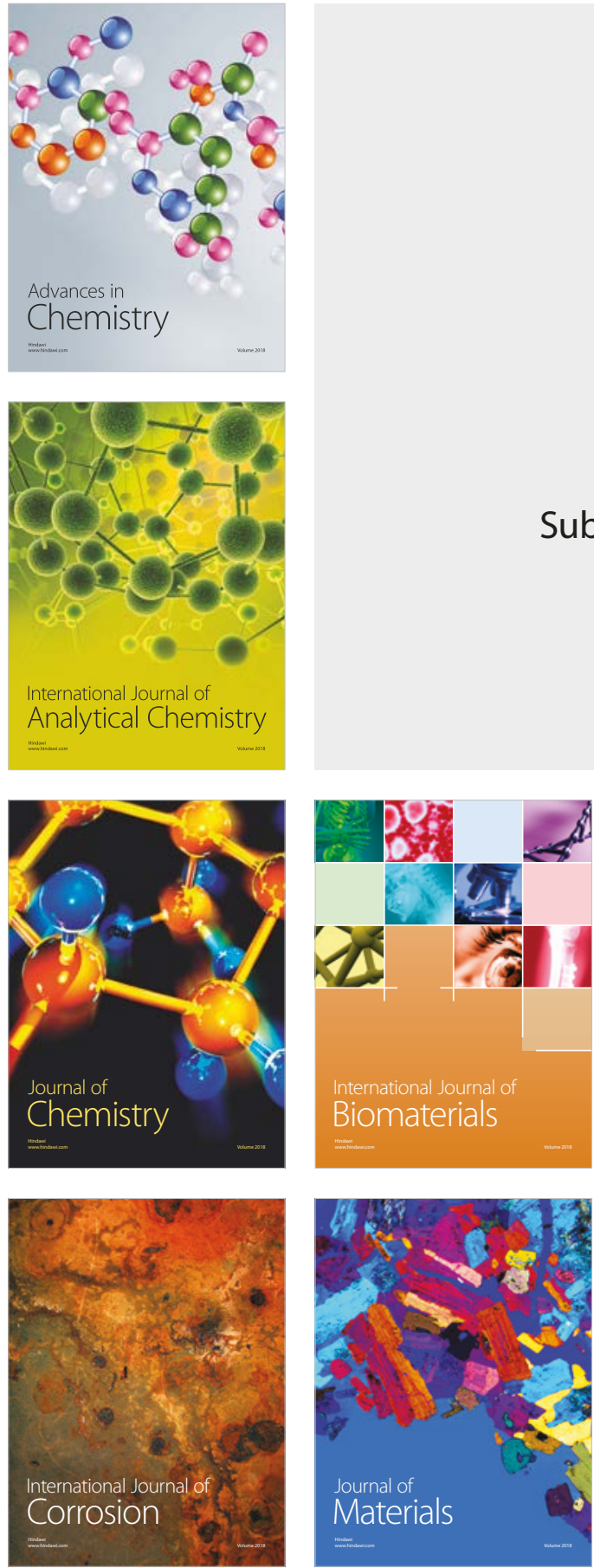

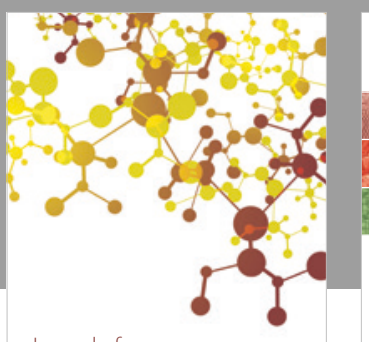

Journal of

Applied Chemistry
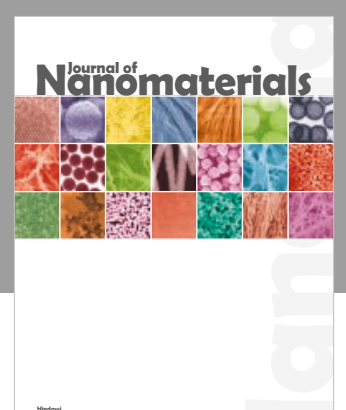

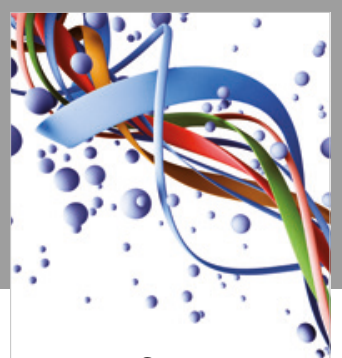

Scientifica

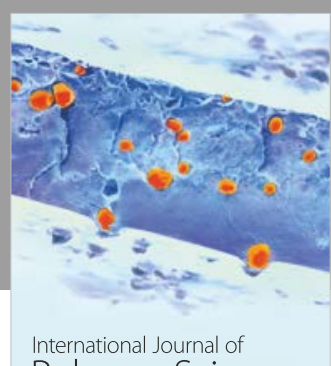

Polymer Science

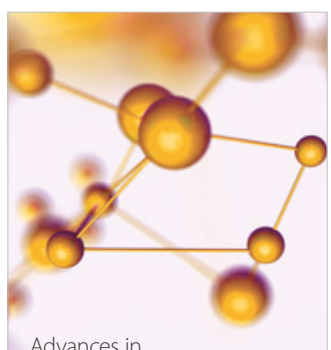

Physical Chemistry
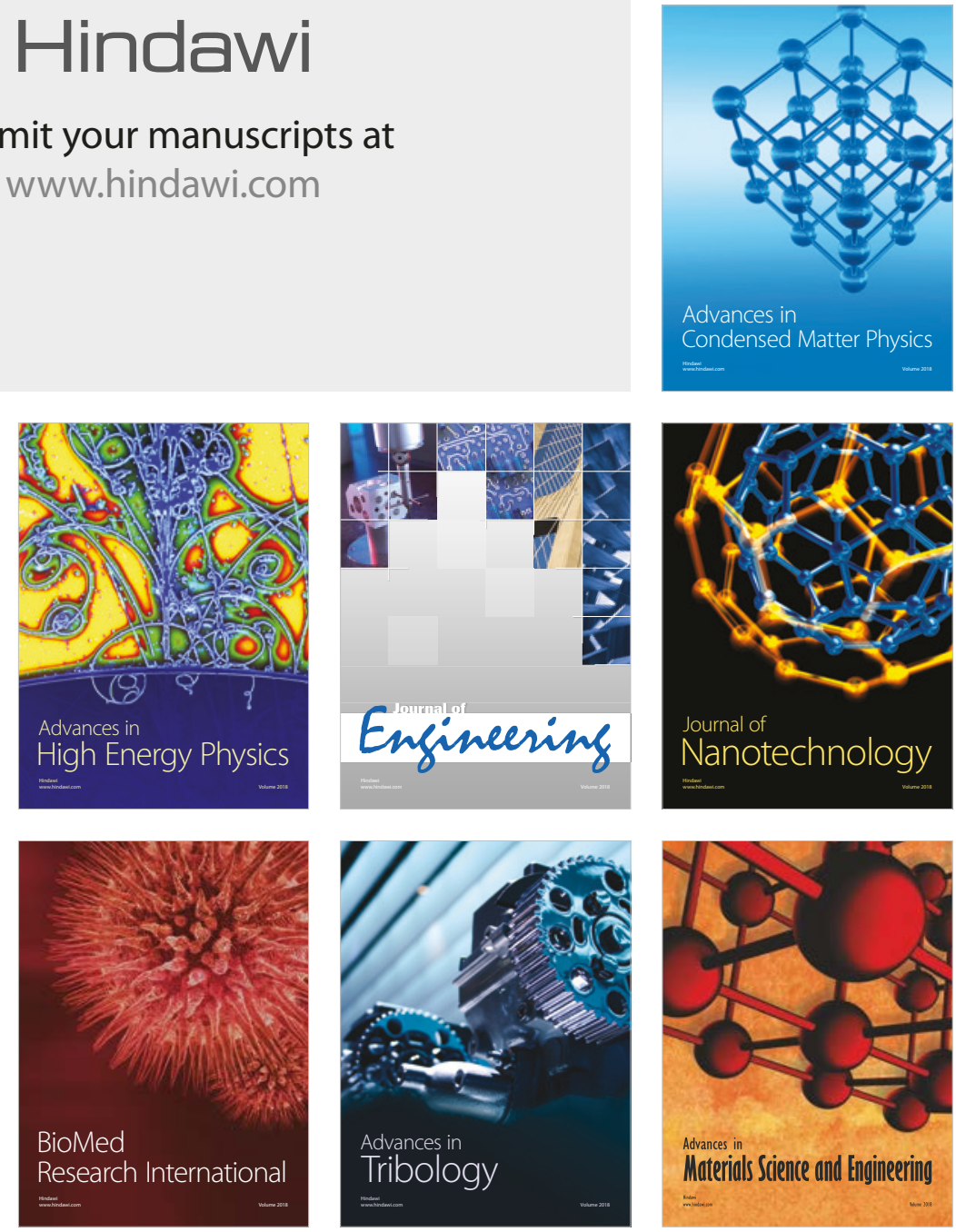